\title{
Assessing the contribution of rare-to-common protein-coding variants to circulating metabolic biomarker levels via 412,394 UK Biobank exome sequences
}

Abhishek Nag${ }^{1}$, Lawrence Middleton ${ }^{1}$, Ryan S. Dhindsa ${ }^{2,3}$, Dimitrios Vitsios ${ }^{1}$, Eleanor Wigmore ${ }^{1}$, Erik L. Allmann ${ }^{1}$, Anna Reznichenko ${ }^{4}$, Keren Carss ${ }^{1}$, Katherine R. Smith ${ }^{1}$, Quanli Wang ${ }^{2}$, Benjamin Challis ${ }^{4}$, Dirk S. Paul ${ }^{1}$, Andrew R. Harper ${ }^{1}$, Slavé Petrovski ${ }^{1}$

${ }^{1}$ Centre for Genomics Research, Discovery Sciences, BioPharmaceuticals R\&D, AstraZeneca, Cambridge, UK

${ }^{2}$ Centre for Genomics Research, Discovery Sciences, BioPharmaceuticals R\&D, AstraZeneca, Waltham, USA

${ }^{3}$ Department of Molecular and Human Genetics, Baylor College of Medicine and Jan and Dan Duncan Neurological Research Institute at Texas Children's Hospital, Houston, TX 77030, USA ${ }^{4}$ Translational Science and Experimental Medicine, Research and Early Development, Cardiovascular, Renal and Metabolism (CVRM), BioPharmaceuticals R\&D, AstraZeneca, Gothenburg, Sweden

\section{Corresponding author:}

Slavé Petrovski

Vice-President, Centre for Genomics Research,

Discovery Sciences, BioPharmaceuticals R\&D

AstraZeneca

Cambridge

United Kingdom

NOTE: This preprint reports new research that has not been certified by peer review and should not be used to guide clinical practice. Email: slav.petrovski@astrazeneca.com 
medRxiv preprint doi: https://doi.org/10.1101/2021.12.24.21268381; this version posted December 30, 2021. The copyright holder for this preprint (which was not certified by peer review) is the author/funder, who has granted medRxiv a license to display the preprint in

All rights reserved. No reuse allowed without permission.

\section{Abstract}

2

3 Genome-wide association studies have established the contribution of common and low

4 frequency variants to metabolic biomarkers in the UK Biobank (UKB); however, the role of

5 rare variants remains to be assessed systematically. We evaluated rare coding variants for

6198 metabolic biomarkers, including metabolites assayed by Nightingale Health, using

7 exome sequencing in participants from four genetically diverse ancestries in the UKB

$8 \quad(\mathrm{~N}=412,394)$. Gene-level collapsing analysis - that evaluated a range of genetic

9 architectures - identified a total of 1,303 significant relationships between genes and

10 metabolic biomarkers $\left(p<1 \times 10^{-8}\right)$, encompassing 207 distinct genes. These include

11 associations between rare non-synonymous variants in GIGYF1 and glucose and lipid

12 biomarkers, SYT7 and creatinine, and others, which may provide insights into novel disease

13 biology. Comparing to a previous microarray-based genotyping study in the same cohort, we

14 observed that $40 \%$ of gene-biomarker relationships identified in the collapsing analysis were

15 novel. Finally, we applied Gene-SCOUT, a novel tool that utilises the gene-biomarker

16 association statistics from the collapsing analysis to identify genes having similar biomarker

17 fingerprints and thus expand our understanding of gene networks. 
medRxiv preprint doi: https://doi.org/10.1101/2021.12.24.21268381; this version posted December 30, 2021. The copyright holder for this preprint (which was not certified by peer review) is the author/funder, who has granted medRxiv a license to display the preprint in

All rights reserved. No reuse allowed without permission.

\section{Introduction}

19 Metabolic blood biomarkers represent intermediate or end products of biochemical pathways

20 that can be used to diagnose and monitor human disease. The application of metabolic

21 biomarkers as intermediate traits to dissect the genetic basis of complex human diseases is

22 well-established. Investigating the genetic underpinnings of blood biomarkers can offer novel

23 insights into human disease mechanisms and, in turn, provide potential therapeutic targets.

24 Large-scale genome-wide association studies (GWAS) have so far identified hundreds of genetic loci that regulate blood biomarker and metabolite levels ${ }^{1-11}$; however, difficulty in mapping these loci to causal genes and interpreting functional effects of non-coding variants have stymied the clinical impact for many of these associations ${ }^{12}$.

The UK Biobank (UKB) ${ }^{13}$ is a large population-based resource of $\sim 500,000$ participants with genetic data linked to a diverse set of phenotypic measurements. Genotype data from microarrays and large population-based imputation panels have helped establish the contribution of common and low frequency variants towards blood biomarkers in the UKB ${ }^{14}$. The availability of exome sequences in the same population now allows for the exploration of rare coding variants regulating metabolic blood biomarkers. Associations for rare coding variants have demonstrably greater translational potential given their larger effect sizes ${ }^{15}$ and our ability to more directly interpret their functional impact ${ }^{16}$.

Using exome sequences from 412,394 unrelated participants across multiple genetic ancestries in the UKB, we present findings of variant-level and gene-level (collapsing) association tests for 198 metabolic blood biomarkers. We then introduce a novel tool, Gene-

41 SCOUT, that utilises this rich catalogue of gene-biomarker association statistics to identify

42 genes with similar biomarker fingerprints as a given (target) gene of interest and expand our 43 understanding of gene networks. 
medRxiv preprint doi: https://doi.org/10.1101/2021.12.24.21268381; this version posted December 30, 2021. The copyright holder for this preprint (which was not certified by peer review) is the author/funder, who has granted medRxiv a license to display the preprint in

All rights reserved. No reuse allowed without permission.

\section{Results}

45 In this study, we analysed 198 metabolic blood biomarkers, including 30 clinical blood

46 biomarkers related to glucose and lipid metabolism, renal and liver function (Table S1A),

47 and an additional 168 Nightingale assay blood metabolite measurements related to

48 lipoprotein lipids, fatty acids and their compositions, and various other low-molecular weight metabolites ${ }^{17}$ (Table S1B). Most of the metabolic biomarkers pertain to lipid metabolism (77\%) and correlate highly with each other (Figure 2a). Many metabolic biomarkers also demonstrate strong associations with clinical traits documented in the UKB (Figure 2b).

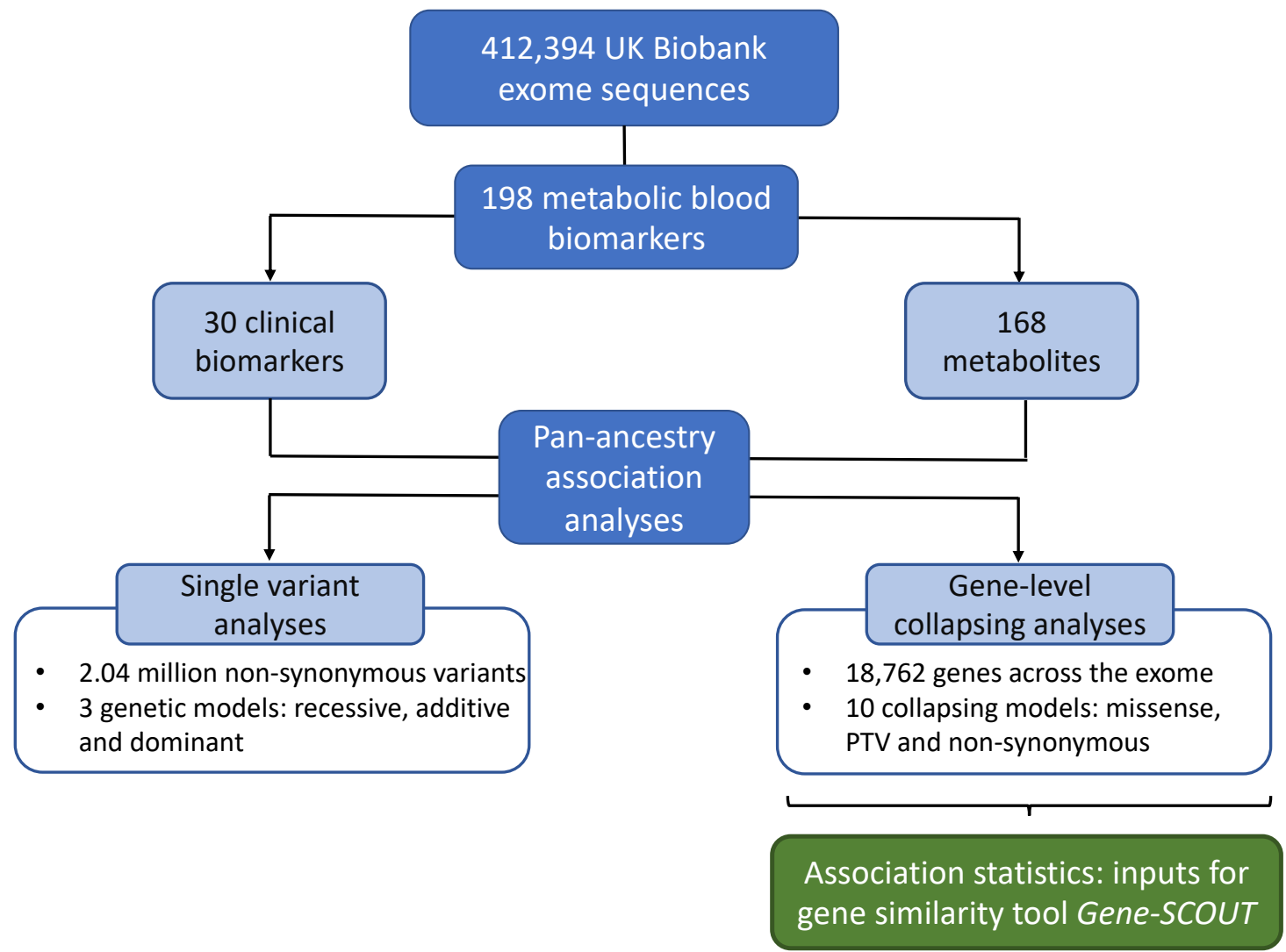

Figure 1: A schematic of the association analyses that were conducted for the metabolic blood biomarkers using the UK Biobank exome sequences

The UK Biobank exome sequences were used to conduct single variant (under 3 genetic models) and gene-level (under 10 collapsing models) association analyses for the clinical blood biomarkers $(\mathrm{N}=30)$ and blood metabolite measurements $(\mathrm{N}=168)$. The gene-level association statistics for these metabolic biomarkers were used as inputs for the gene similarity tool Gene-SCOUT.

We first conducted a single variant analysis between the non-synonymous coding

61 variants ( $\mathrm{N}=2,043,019$ for the European ancestry subset) and the 198 metabolic biomarkers

62 (Figure 1). Excluding the MHC region, 19,351 significant variant-biomarker associations 
medRxiv preprint doi: https://doi.org/10.1101/2021.12.24.21268381; this version posted December 30, 2021. The copyright holder for this preprint (which was not certified by peer review) is the author/funder, who has granted medRxiv a license to display the preprint in All rights reserved. No reuse allowed without permission.

63

64

65

66

67

68

69

70

$\left(p<1 \times 10^{-8}\right)$ were identified in the European subset of UK Biobank, which mapped to 12,217 significant relationships between genes and biomarkers (Tables S2A, S2B). Pruning variants in linkage disequilibrium ( $r^{2}$ threshold of 0.5$)$ resulted in 9,738 significant genebiomarker relationships. Notably, 243 distinct PTVs accounted for 1,366 significant associations, of which 602 (44\%) were attributable to rare PTVs $(\mathrm{MAF}<0.1 \%)$ with large effect sizes (>0.5 SD) (Figure 4a) (Tables S3A, S3B). We identified 28 PTVs with MAF as low as $0.001 \%$ that achieved significance in the ExWAS: these include associations relating to several well-established and biologically plausible relationships such as GOT1 and aspartate aminotransferase, CST3 and cystatin C, APOB and cholesterol biomarkers, ALPL and alkaline phosphatase (Table S3A). Among other PTV findings that may provide new insights into important biology, a rare frameshift variant (MAF=0.03\%) in PLIN1 - a gene known to cause familial lipodystrophy ${ }^{18}$ - was associated with HDL-cholesterol (beta=0.40 $\left.[0.27,0.53], \mathrm{p}=1.6 \times 10^{-9}\right)$, and a rare splice variant $(\mathrm{MAF}=0.09 \%)$ in TNFRSF10B - loss of which has been reported to promote survival of virus-infected liver cells ${ }^{19}$ - was associated with gamma glutamlytransferase (beta $\left.=0.21[0.14,0.28], p=3.8 \times 10^{-9}\right)$ (Table S3A).

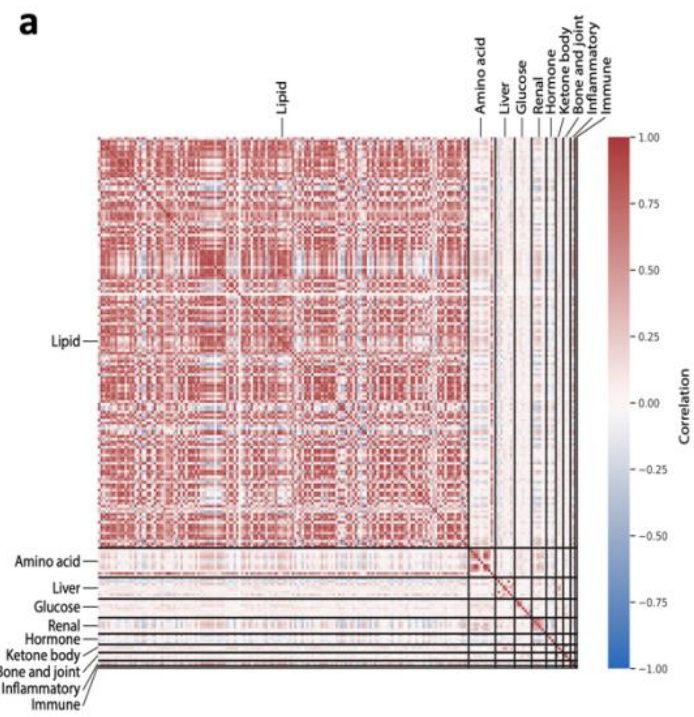

b

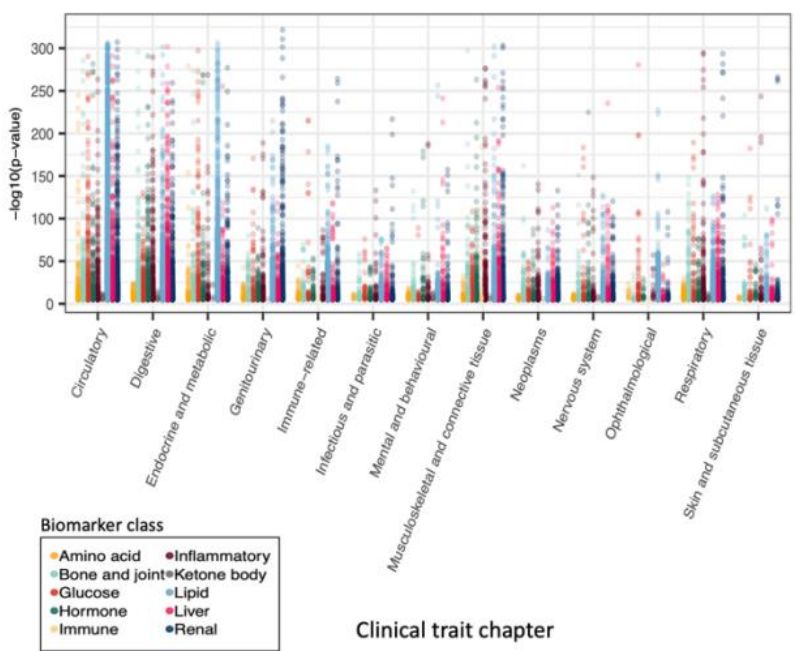

Figure 2: Characteristics of metabolic blood biomarkers analysed in this study The 198 metabolic blood biomarkers analysed in this study were grouped into the following 10 biological classes: lipid, amino acid, liver, glucose, renal, hormone, ketone body, bone and joint, inflammatory, and immune. (a) The plot demonstrates that metabolic biomarkers belonging to the same biological class are correlated with each other. (b) Strong associations (plotted on the Y-axis) were observed between the metabolic biomarkers and 15,719 clinical traits (grouped by chapter) documented in the $\mathrm{UKB}^{20}$. 
medRxiv preprint doi: https://doi.org/10.1101/2021.12.24.21268381; this version posted December 30, 2021. The copyright holder for this preprint (which was not certified by peer review) is the author/funder, who has granted medRxiv a license to display the preprint in All rights reserved. No reuse allowed without permission.

Next, we performed a gene-level collapsing analysis that tests the aggregate effect of rare functional variants in each gene. We employed 10 different models to capture a diverse range of genetic architectures (Methods). In the analysis involving individuals of European ancestry alone, we identified 1,303 significant relationships between genes and metabolic biomarkers $\left(p<1 \times 10^{-8}\right)$ (Tables S4A, S4B; Figures 3a, 3b). Most $(68 \%, 880 / 1,303)$ genebiomarker relationships detected via the collapsing analysis were captured through models that exclusively focused on PTV classes ("ptv" and "ptv5pcnt"), while the remaining $32 \%$ were attributable to models that incorporated missense variants. We detected more significant associations using our "ptv" and "ptv5pcnt" models than a prior study ${ }^{21}$ that also performed gene-level collapsing analysis using the UKB exome sequence data, albeit with a different analytical framework. For instance, associations between PTVs in 12 genes and $\mathrm{HbA1c}$ that we detected were not reported in the other study: this includes the glucose metabolism genes HK1 and G6PC2 (Figure S1). We also extended our gene-level collapsing analysis to include all ancestral groups in the UKB (Methods). This detected an additional 51 significant gene-biomarker relationships (Tables S5A, S5B). For the genebiomarker relationships that were significant only in the pan-ancestry analysis, we did not observe a significant difference in the estimated effect size between the European-only and the pan-ancestry analyses $(p=0.83)$, suggesting that increased statistical power rather than ancestry-specific effects is the more likely reason why these associations were identified in the pan-ancestry analysis. One such association detected exclusively in the pan-ancestry analysis was between recessive carriers of nonsynonymous variants in the membrane transport gene SYT7 and blood creatinine levels (number of QV carriers=5, beta=2.17 $\left.[1.46,2.87], p=1.6 \times 10^{-9}\right)$. With 3 of the 5 carriers observed in the South Asian and African ancestry participants, the pan-ancestry analysis facilitated detection of this association, which was not study-wide significant in the European subset (number of QV carriers=2, beta $=1.17[0.06,2.28], \mathrm{p}=0.04)$. Remarkably consistent with the biomarker findings, recessive carriers of SYT7PTVs demonstrate a increased risk of glomerular disease in the 
medRxiv preprint doi: https://doi.org/10.1101/2021.12.24.21268381; this version posted December 30, 2021. The copyright holder for this preprint (which was not certified by peer review) is the author/funder, who has granted medRxiv a license to display the preprint in All rights reserved. No reuse allowed without permission.

113 pan-ancestry analysis $\left(\mathrm{OR}=92.1[12.1,713.2], \mathrm{p}=2.6 \times 10^{-5}\right)$, but the clinical association on its

114 own is not yet study-wide significant.

115 The significant gene-level relationships from the collapsing analyses encompassed

116207 distinct genes, of which 32 were associated with biomarkers across different biological

117 classes (Figure 3c). This includes GIGYF1, a tyrosine kinase receptor signalling protein, in

118 which rare PTVs were associated with biomarkers of glucose [glucose (beta=0.59

$\left.119[0.42,0.76], p=7.9 \times 10^{-12}\right)$ and HbA1c $\left(\right.$ beta $\left.\left.=0.73[0.57,0.88], p=4.5 \times 10^{-20}\right)\right]$ and cholesterol

120 metabolism [total cholesterol (beta=-0.66 [-0.82,-0.50], $\left.\mathrm{p}=2.0 \times 10^{-15}\right)$, LDL-cholesterol (beta=-

$\left.1210.61[-0.78,-0.45], p=3.4 \times 10^{-13}\right)$ and apolipoprotein $B\left(\right.$ beta $\left.\left.=-0.60[-0.77,-0.44], p=1.3 \times 10^{-12}\right)\right]$.

122 Additionally, among clinical traits documented in the $\mathrm{UKB}^{20}$, significant associations were

123 observed for rare PTVs in GIGYF1 with the risk of hypothyroidism (OR=4.2 [2.7,6.6],

$\left.124 \mathrm{p}=7.1 \times 10^{-9}\right)$ and type 2 diabetes $\left(\mathrm{OR}=4.0[2.7,5.8], \mathrm{p}=1.0 \times 10^{-10}\right)$. Since hypothyroidism is

125 known to raise LDL-cholesterol levels, we subsequently tested the GIGYF1-LDL-cholesterol

126 association adjusted for a diagnosis of hypothyroidism. The signal between GIGYF1 PTVs

127 and LDL-cholesterol (adjusted for the effect of statins) remained significant upon adjusting

128 for hypothyroidism (beta=-0.55 $[-0.71,-0.38] ; \mathrm{p}=6.2 \times 10^{-11}$ ), suggesting that the GIGYF1 locus

129 likely influences cholesterol levels independent of solely thyroid hormone-mediated

130 pathways. Thus, by leveraging information from over 400,000 UKB exomes, our study

131 provides a more comprehensive picture regarding GIGYF1's biomarker fingerprint and

132 associated clinical traits, expanding on previously reported common ${ }^{7}$ and rare variant 133 associations ${ }^{21,22}$ at this locus.

134 We observed that adjusting biomarkers for medications that influence their levels can 135 also improve detection of associations: $31 / 84$ (37\%) significant gene-biomarker relationships

136 for apolipoprotein B, LDL-cholesterol, total cholesterol, and urate from the collapsing

137 analysis were detected only after we adjusted their values for commonly prescribed

138 medications (Table S4A). This includes association between putatively damaging missense

139 variants and PTVs in HMGCR ("flexdmg" model) and LDL-cholesterol (medication-adjusted:

140 beta $=-0.19$ and $p=1.7 \times 10^{-11}$; medication-unadjusted: beta $=-0.15$ and $p=6.1 \times 10^{-8}$ ), which 
medRxiv preprint doi: https://doi.org/10.1101/2021.12.24.21268381; this version posted December 30, 2021. The copyright holder for this preprint (which was not certified by peer review) is the author/funder, who has granted medRxiv a license to display the preprint in

All rights reserved. No reuse allowed without permission.

141 validates the value of medication adjustment to untangle the effects of therapeutic

142 intervention vs natural aberration of $H M G C R$. Moreover, for gene-biomarker relationships

143 that were significantly associated in both the medication-unadjusted and the medication-

144 adjusted analyses ( $N=52)$, the absolute effect sizes were observably higher in the latter

145 (Figure S2), but the difference was not statistically significant in the current sample (Mann

146 Whitney $p=0.28)$.

a

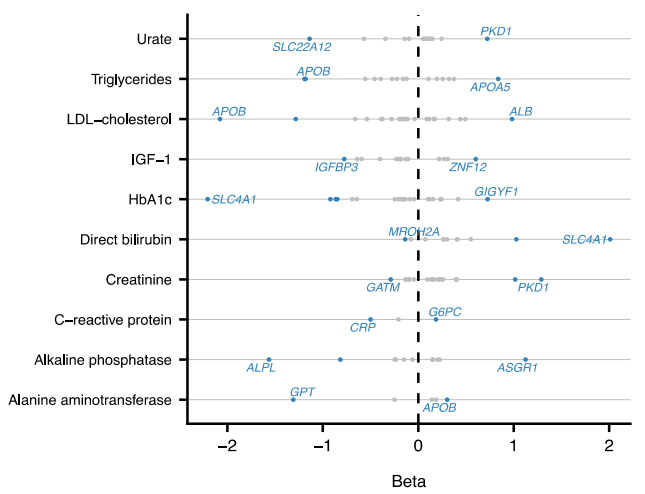

b

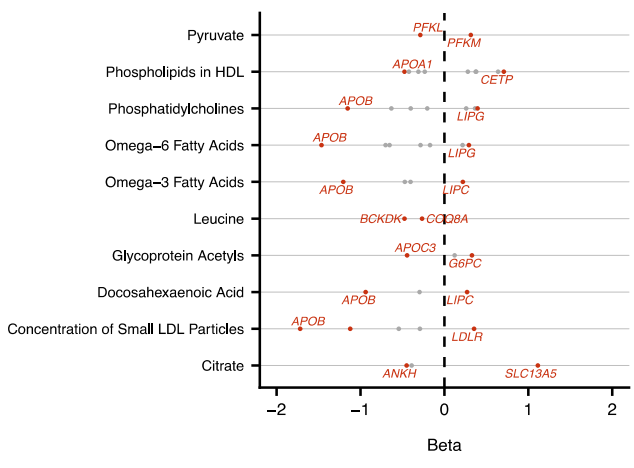

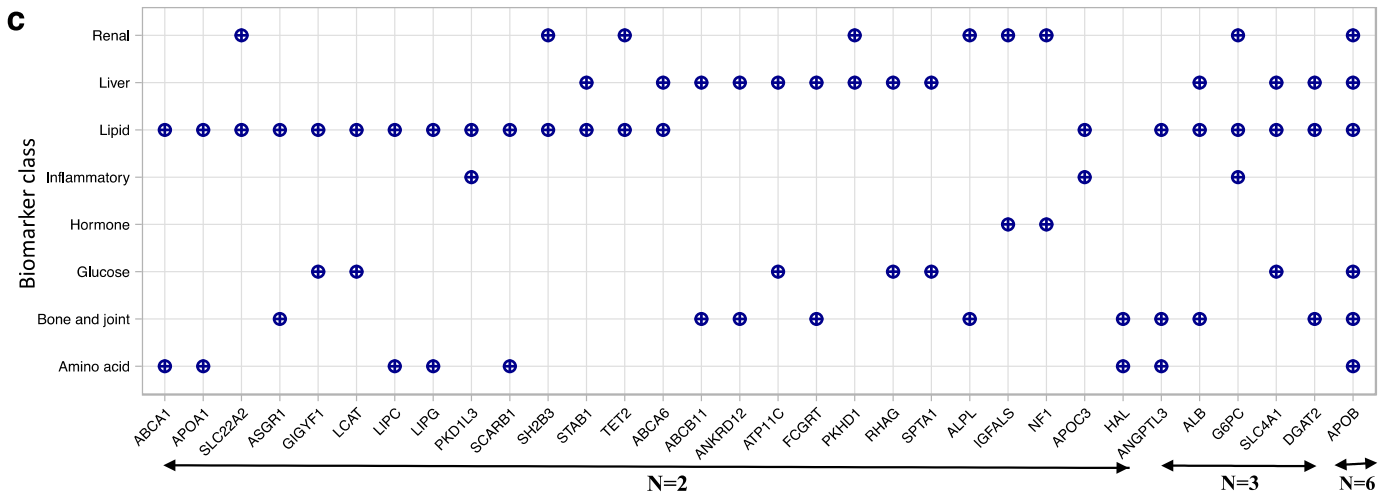

147

148

149

150

151

152

153

154

155

156

157

158

159

160

161

Figure 3: Significant relationships between genes and metabolic blood biomarkers identified in the collapsing analysis

(a, b) Significant gene relationships $\left(p<1 \times 10^{-8}\right)$ identified for select clinical biomarkers and metabolites in the collapsing analysis have been shown. The genes with the highest absolute effect sizes for each have been labelled.

(c) The plot lists the 32 genes that were significantly associated $\left(\mathrm{p}<1 \times 10^{-8}\right)$ with metabolic biomarkers across two or more biological classes in the collapsing analysis. For each such gene, the corresponding biological classes have been indicated.

\section{Gene-level collapsing analysis: capturing allelic series}

We observed that $17 \%(215 / 1,303)$ of significant relationships between genes and metabolic biomarkers from the collapsing analysis did not achieve significance in the respective variant-level ExWAS (Table S6). Next, we also compared the gene-biomarker relationships that achieved significance in the collapsing analysis (Tables S4A, S7) and the 
medRxiv preprint doi: https://doi.org/10.1101/2021.12.24.21268381; this version posted December 30, 2021. The copyright holder for this preprint (which was not certified by peer review) is the author/funder, who has granted medRxiv a license to display the preprint in All rights reserved. No reuse allowed without permission.

162 microarray-based GWAS ${ }^{14}$ (as per a less stringent significance threshold: $p<1 \times 10^{-7}$ ) for the

16332 biomarkers ( 28 blood and 4 urinary biomarkers) analysed in both studies. Of the

164 significant gene-biomarker relationships identified in the collapsing analysis, 40\% (142/357)

165 were not detected in the microarray-based GWAS (Table S8). These include associations

166 for well-known drug target genes such as HMGCR (with LDL-cholesterol) and PPARG (with

167 HDL-cholesterol). Furthermore, the effect size estimates were significantly higher in the

168 collapsing analysis than in microarray-based GWAS for 215 gene-biomarker relationships

169 detected via both approaches (Mann-Whitney $\left.p=8.0 \times 10^{-6}\right)$ (Table S9; Figure 4b). One likely

170 explanation for this is that by testing aggregate effects of rare putative functional variants in

171 a gene, associations arising from collapsing analysis are enriched for larger effects (Figure

172 4c). Collectively, these results highlight that application of a gene-based rare variant

173 collapsing analysis to large-scale exome sequencing can increase power to capture associations that are driven by an allelic series, and thus expand our understanding of the

175 genetic architecture of traits, especially where a lot of success has already been achieved

176 through traditional microarray-based GWAS.

SLC4A1, which encodes a chloride/bicarbonate anion exchange protein in the red cell membrane, represents one such gene for which multiple signals were detected in the gene-

179 level collapsing analysis but not in the ExWAS. We observed 32 carriers for 28 distinct SLC4A1

180 PTVs, of which 25 (89\%) were private (i.e., observed in a single carrier) (Figure S3). Overall,

181 SLC4A1 PTVs were significantly associated with a strong reduction in HbA1c (beta=-2.2 [-2.6,-

$1821.8], p=1.4 \times 10^{-25}$ ) and LDL-cholesterol (beta=-1.0 $[-1.4,-0.7], p=8.0 \times 10^{-9}$ ), while also showing

183 strong increases in total bilirubin (beta=1.7 $[1.3,2.0], p=1.1 \times 10^{-22}$ ) and direct bilirubin

184 (beta=2.0 $\left.[1.7,2.4], \mathrm{p}=1.8 \times 10^{-28}\right)$. Among clinical phenotypes, SLC4A1 PTVs are significantly associated with disorders of reduced red cell membrane stability such as hereditary

186 spherocytosis and hereditary haemolytic anaemia, but not with any phenotype related to

187 glucose or lipid metabolism $\left(p<1 \times 10^{-5}\right)$. Similarly, in ClinVar, several missense and loss-of- 
medRxiv preprint doi: https://doi.org/10.1101/2021.12.24.21268381; this version posted December 30, 2021. The copyright holder for this preprint (which was not certified by peer review) is the author/funder, who has granted medRxiv a license to display the preprint in

All rights reserved. No reuse allowed without permission.

188 function mutations in this gene are reported as pathogenic for hereditary spherocytosis.

189 Therefore, we further tested the SLC4A1-biomarker associations after adjusting for the

190 diagnosis of hereditary spherocytosis or hereditary haemolytic anaemia and relevant blood

191 cell indices, including red cell distribution width (RDW) and mean corpuscular haemoglobin
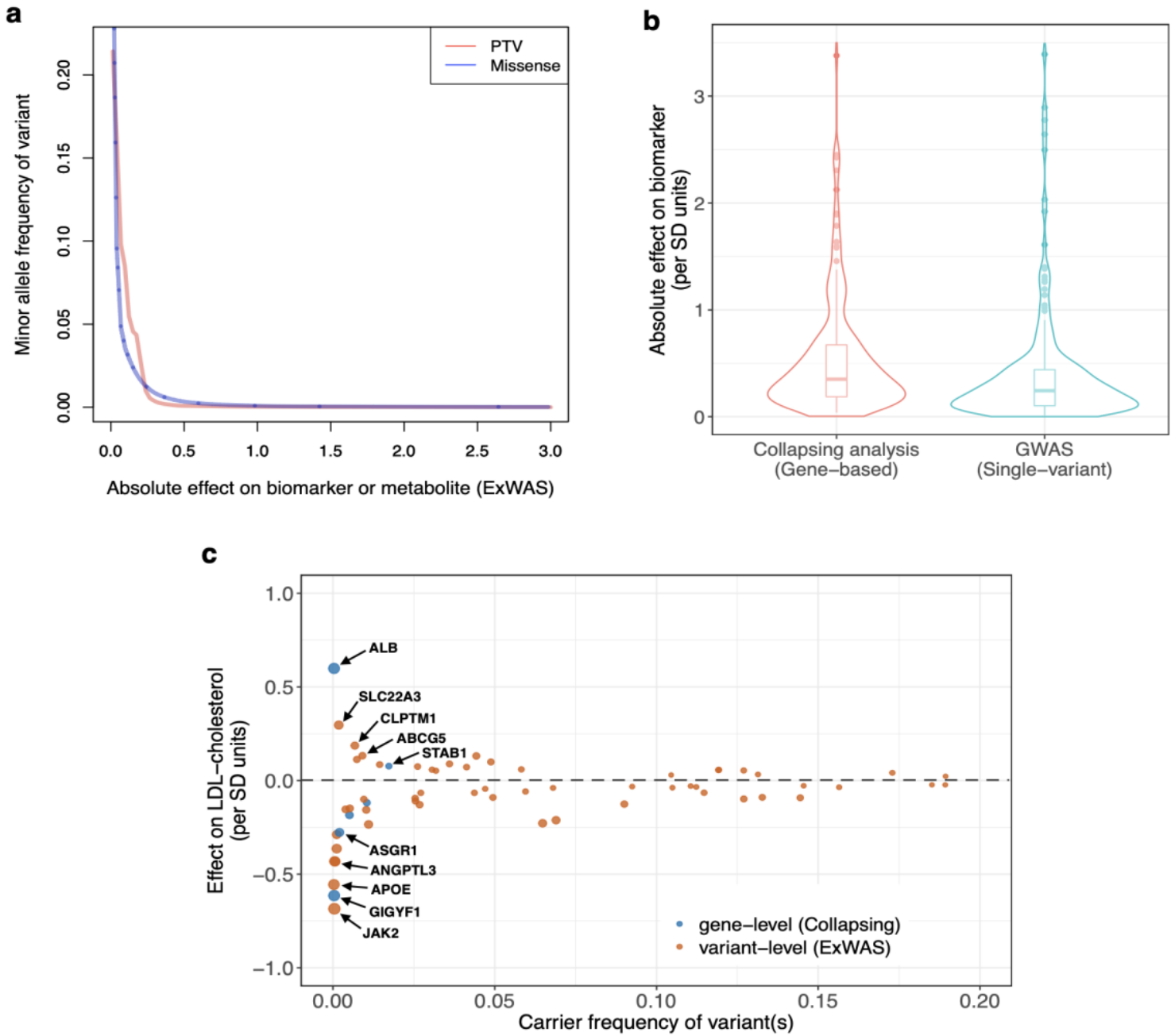

192

\section{Figure 4: Effects of coding variants on metabolic blood biomarkers}

(a) Absolute effect sizes for missense variants and PTVs significantly associated $\left(p<1 \times 10^{-8}\right)$ with metabolic biomarkers in the single variant analysis (ExWAS) as a function of their minor allele frequency (in cases where a missense variant or a PTV was significantly associated with more than one biomarker, the association with the highest absolute effect size was selected). (b) The effect sizes estimated in the gene-based collapsing analysis and the Sinnott-Armstrong et al microarraybased GWAS $^{14}$ were compared for the gene-biomarker relationships that were significantly associated in both $(\mathrm{N}=215)$. For each significant gene-biomarker relationship, the collapsing model (from the collapsing analysis) and the individual variant (from the microarray-based GWAS) with the highest absolute effect sizes were selected. The effect sizes estimated in the collapsing analysis were significantly higher than that in the GWAS (Mann-Whitney $p=8.0 \times 10^{-6}$ ). (c) Comparing effect sizes for individual variants and aggregate of rare variants (in a gene) that were significantly associated $\left(p<1 \times 10^{-8}\right)$ with LDL-cholesterol. Some examples of genes significantly associated with LDLcholesterol have been highlighted. The Y-axis has been capped at 1 SD units for visual clarity. 
medRxiv preprint doi: https://doi.org/10.1101/2021.12.24.21268381; this version posted December 30, 2021. The copyright holder for this preprint (which was not certified by peer review) is the author/funder, who has granted medRxiv a license to display the preprint in

All rights reserved. No reuse allowed without permission.

207

208

209

210

211

212

213

214

215

216

217

218

219

220

221

222

223

224

225

226

227

228

229

230

231

232

233

concentration (MCHC). The gene-based SLC4A1 PTV signals remained significant in the adjusted analyses (Table S10). Although PTVs in this gene may be independently associated with biomarkers of glucose, lipid and bilirubin metabolism, we cannot rule out the possibility of under-reporting of hereditary spherocytosis and hereditary haemolytic anaemia in the UKB that explains these observations. The SLC4A1 enigma is consistent with previous reports of other red blood cell loci that have also been significantly associated with $\mathrm{HbA} 1 \mathrm{c}^{23}$.

\section{Gene-SCOUT: estimating gene similarity based on cohort statistics from collapsing analysis}

We considered the opportunity to leverage this new and rich catalogue of gene-level association statistics from the collapsing analysis to determine genes with similar biomarker fingerprints. To achieve this, we developed a gene similarity tool 'Gene-SCOUT'24, that solely uses the gene-level collapsing analysis statistics across the studied biomarkers to identify genes with the most comparable biomarker genetic associations as a given gene of interest. No other information is used in constructing the gene similarity scores. Since this tool estimates gene similarity for an index gene by selecting features based on the significance cut-off of $p<1 \times 10^{-5}$, gene neighbours could not be determined for genes that did not achieve association $\mathrm{p}<1 \times 10^{-5}$ with any biomarker feature. Accordingly, for our feature set comprising of 198 biomarkers, we were able to determine gene similarity for $3 \%$ $(536 / 18,762)$ of human protein-coding genes. To illustrate Gene-SCOUT's application, we selected the 24 genes that were significantly associated $\left(p<1 \times 10^{-8}\right)$ with LDL-cholesterol in the collapsing analysis. We used each gene in this set as a seed gene to construct a network figure that demonstrates their respective gene neighbours (Figure 5). Using $A P O B$ as an example, we observe that genes with the most comparable biomarker fingerprint as APOB include: ABCA1, ACVR1, APOC3, ANGPTL3, ASGR1, ASXL1, BTNL9, GIGYF1, HIST2H2BE, HMGCR, NPC1L1, PCSK9, PDE3B, PKD1L3, RRBP1, SLC4A1, TM6SF2 and ZNF229. For some of these genes (e.g., ZNF229, ACVR1), the links with lipid metabolism 
medRxiv preprint doi: https://doi.org/10.1101/2021.12.24.21268381; this version posted December 30, 2021. The copyright holder for this preprint (which was not certified by peer review) is the author/funder, who has granted medRxiv a license to display the preprint in

All rights reserved. No reuse allowed without permission.

234 appear to be novel, in addition to the recently described relationships for GIGYF121,22.

235 Inhibition of $A P O B$, such as through mipomersen, is known to be clinically effective in

236 reducing blood cholesterol levels. Remarkably, 5 (namely, APOC3, ANGPTL3, HMGCR,

237 NPC1L1 and PCSK9) of the 18 genes (28\%) determined to have similar cohort-level genetic

238 associations for biomarkers as $A P O B$ are also targets of lipid-lowering drugs that are already

239 approved or in various stages of development (https://www.fda.gov/drugs).

240

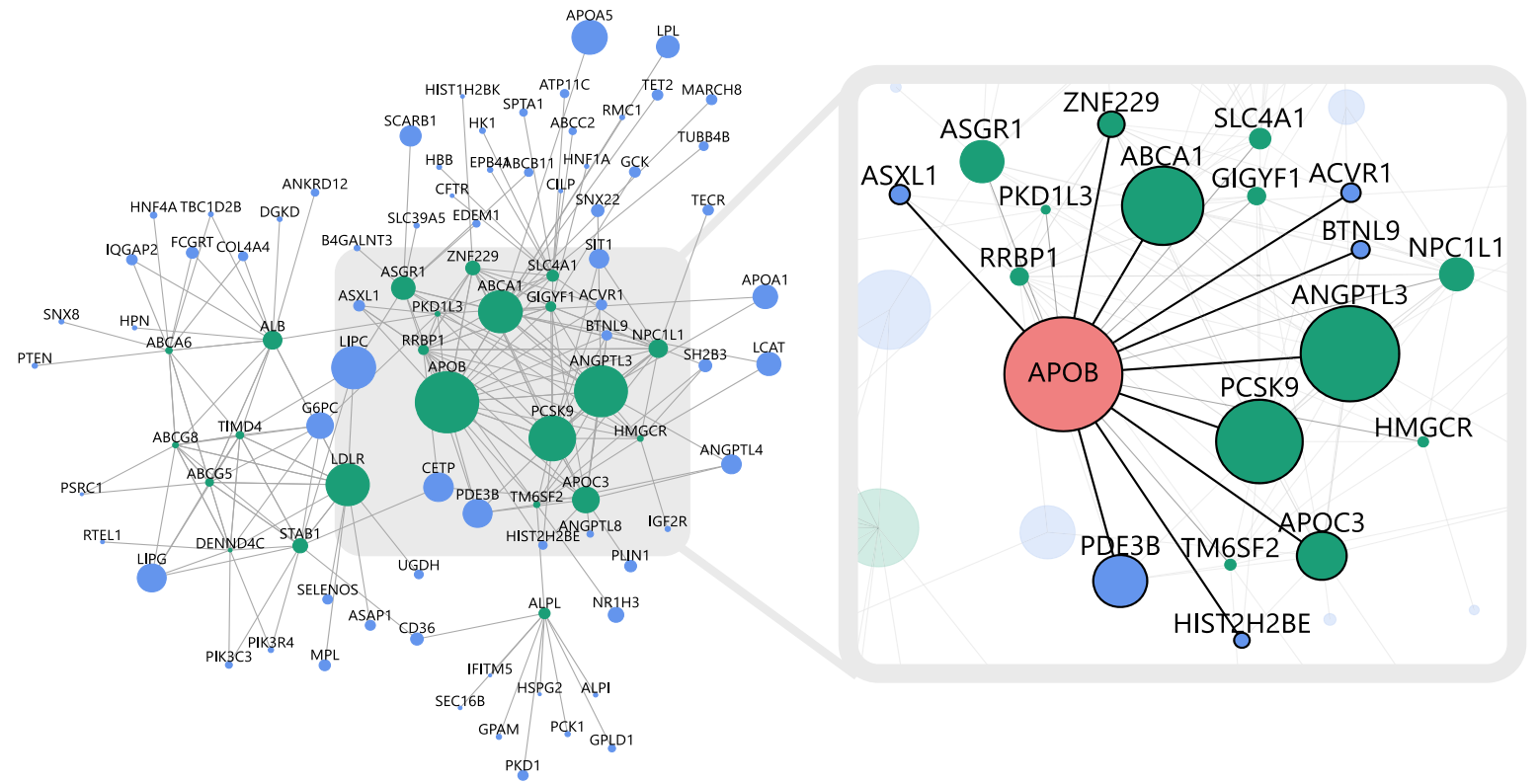

Figure 5: Network figure demonstrating the gene neighbours i.e., genes with most similar biomarker genetic signals, as the set of genes that were significantly associated with LDL-choleserol in the collapsing analysis

The 24 genes that were significantly associated $\left(p<1 \times 10^{-8}\right)$ with LDL-cholesterol in the collapsing analysis were used as seed genes (green nodes) to construct a network figure demonstrating respective gene neighbours (edges). Non-seed genes are represented using blue nodes. The size of a gene node corresponds to the number of features (of total 198) that the gene is associated with at $\mathrm{p}<1 \times 10^{-5}$. The inset demonstrates the genes with most similar biomarker signature as $A P O B-$ these include the ten closest genes for $A P O B$ as the seed gene (black edges) and other seed genes that have $A P O B$ among their ten closest genes (grey edges). 
medRxiv preprint doi: https://doi.org/10.1101/2021.12.24.21268381; this version posted December 30, 2021. The copyright holder for this preprint (which was not certified by peer review) is the author/funder, who has granted medRxiv a license to display the preprint in

All rights reserved. No reuse allowed without permission.

\section{Discussion}

252 We used the 454,796 UK Biobank exome sequences to explore the contribution of private-to-

253 rare-to-common protein-coding variation for 30 clinical biomarkers and 168 metabolite

254 measurements. By adopting variant- and gene-level analysis frameworks and assessing the

255 full allelic frequency spectrum, we have expanded our understanding of the genetic

256 architecture of metabolic biomarkers that have previously been studied through microarray

257 data. The finding that $17 \%$ of gene-biomarker relationships detected in the gene-level

258 collapsing analysis were not identified in the single variant analysis demonstrates the power

259 of testing an aggregate effect of rare variants in a gene encompassing a range of genetic

260 architectures. We also illustrated how adjusting biomarker values for commonly prescribed

261 medications can improve signal detection.

262 There are several strengths of our study that might have implications for identifying or

263 validating drug targets. First, by virtue of focusing on coding variants, the observed

264 associations could provide a more causal link between a gene and a blood biomarker ${ }^{25-28}$.

265 Moreover, association signals emerging from collapsing analysis are driven by an aggregate

266 effect of multiple rare variants (allelic series) that tend to be less impacted by local LD

267 structure. This contrasts with associations identified in microarray-based GWAS that often

268 map to non-coding regions of the genome or to regions of extensive LD, making it more

269 challenging to pinpoint the underlying causal variants.

270 Associations involving putative functional variants can also indicate the desired

271 modulation of the target gene e.g., upregulation or downregulation of the target gene

272 product, required to mitigate the risk of the disease related to the associated biomarker. For

273 instance, we observed a total of 182 associations for rare (MAF $<0.1 \%$ ) PTVs with the 30

274 blood biomarkers, which is $>3$-fold more than the 53 conditionally independent PTV

275 associations (for the same set of blood biomarkers) reported in the microarray-based

276 analysis ${ }^{14}$. 
medRxiv preprint doi: https://doi.org/10.1101/2021.12.24.21268381; this version posted December 30, 2021. The copyright holder for this preprint (which was not certified by peer review) is the author/funder, who has granted medRxiv a license to display the preprint in

All rights reserved. No reuse allowed without permission.

We also introduce a novel tool (Gene-SCOUT) that utilises all the gene-level

278 collapsing analysis statistics across the 198 studied biomarkers to estimate a 'similarity'

279 metric between genes. With the aid of specific examples, we were able to demonstrate that

280 this approach can successfully identify genes with similar biomarker fingerprints.

281 While there are certain advantages of using blood biomarkers to dissect the genetics

282 of complex human diseases, including greater statistical power offered by quantitative traits

283 and better insights into biological pathways underlying associations, further work is

284 necessary to establish the causal relationship between genetic loci identified using

285 biomarkers or metabolites and the related disease(s). For instance, we observed

286 associations between certain biomarkers and variants in genes that encode them (e.g., $A L B$

287 with albumin, and CST3 with cystatin C) - although such associations serve as excellent

288 positive controls that demonstrate the robustness of our analysis framework, they may not

289 offer novel insights into disease pathophysiology.

290 Using the largest collection of exome sequences linked to a diverse set of circulating

291 metabolic biomarkers, we demonstrate the value of this resource to enhance our

292 understanding of human diseases, and potentially, provide novel therapeutic targets focused

293 on mimicking natural human genetic discoveries. Our study also strongly supports the use of

294 a gene-based collapsing framework to uncover gene-biomarker relationships that are driven

295 by an aggregate effect of multiple rare, non-synonymous variants.

296 
medRxiv preprint doi: https://doi.org/10.1101/2021.12.24.21268381; this version posted December 30, 2021. The copyright holder for this preprint (which was not certified by peer review) is the author/funder, who has granted medRxiv a license to display the preprint in

All rights reserved. No reuse allowed without permission.

\section{Methods}

298

299 UK Biobank (UKB) Resource

300 The UKB resource ${ }^{13}$ is a prospective cohort study of $\sim 500,000$ individuals from across the

301 United Kingdom, aged between 40 and 69 years. The average age at recruitment for the

302 sequenced participants was 56.5 years and $54 \%$ of the sequenced cohort are females.

303 Participant data, obtained through questionnaires and assessment visits, include health

304 records that are periodically updated by the UKB, self-report survey information, linkage to

305 death and cancer registries, urine and blood biomarkers, imaging data, accelerometer data

306 and various other phenotypic endpoints ${ }^{13}$. All study participants provided informed consent.

307 For this study, data from the UKB resource was accessed under the application number

30826041.

309

310

\section{Metabolic blood biomarkers}

311 Routine clinical blood biomarkers related to glucose and lipid metabolism, renal and liver

312 function, among others $(\mathrm{N}=30)$, were measured in the majority of the $\sim 500,000 \mathrm{UKB}$

313 participants (Table S1A). Additionally, 168 blood metabolites, including lipoprotein lipids,

314 fatty acids and their compositions, and various low-molecular weight metabolites, were

315 profiled in a subset of $\sim 120,000$ UKB participants by Nightingale Health using nuclear

316 magnetic resonance spectroscopy ${ }^{17}$ (Table S1B). Samples with a 'quality control (QC) flag'

317 for the blood metabolites were excluded. In total, we analysed 198 metabolic blood

318 measures: 30 clinical biomarkers and 168 metabolites. We applied rank-based inverse-

319 normal transformation to the measurements prior to performing association analyses.

320 For four blood biomarkers (LDL-cholesterol, total cholesterol, apolipoprotein B and

321 urate) we adjusted for the effect of commonly prescribed medications known to influence

322 their levels. For LDL-cholesterol, total cholesterol and apolipoprotein B, we adjusted for the

323 effect of statins based on their 'statin adjustment factors', previously estimated in the UKB as

$3240.684,0.749$ and 0.719 , respectively ${ }^{14}$. Similarly, we adjusted urate for the effect of 
medRxiv preprint doi: https://doi.org/10.1101/2021.12.24.21268381; this version posted December 30, 2021. The copyright holder for this preprint (which was not certified by peer review) is the author/funder, who has granted medRxiv a license to display the preprint in

All rights reserved. No reuse allowed without permission.

325 allopurinol based on an 'allopurinol adjustment factor (0.810)', calculated using an approach

326 identical to that described for statins ${ }^{14}$.

\section{Whole-exome sequencing and bioinformatics pipeline}

329 Whole-exome sequences for 454,988 UKB participants were generated at the Regeneron

330 Genetics Center as part of a pre-competitive data generation collaboration between AbbVie,

331 Alnylam Pharmaceuticals, AstraZeneca, Biogen, Bristol-Myers Squibb, Pfizer, Regeneron

332 and Takeda ${ }^{29}$. The exome sequencing procedure and the relevant QC steps have been

333 detailed previously in Szustakowski et al $(2021)^{29}$ and Wang et al $(2021)^{20}$. The FASTQ

334 sequences that were made available were first aligned, following which, single nucleotide

335 variants (SNVs) and small indels were called using Illumina's DRAGEN Bio-IT Platform

336 Germline Pipeline v3.0.7 on the Amazon Web Services cloud compute platform available at

337 AstraZeneca's Centre for Genomics Research. SNPEff v4. $3^{30}$ was used to annotate the

338 'most damaging effect' predicted for each protein coding variant. In addition, we used certain

339 other bioinformatic tools such as missense tolerance ratio (MTR) scores ${ }^{31}$ to identify regions

340 of protein coding genes under constraint for missense variants, and REVEL ${ }^{32}$ to prioritise

341 coding variants based on their predicted deleteriousness. Further details on how these tools

342 were applied to the UKB exome sequencing dataset have been previously described ${ }^{20}$.

343

\section{Selection of UKB samples for the association analyses}

Prior to performing the association analyses, we excluded samples from the available UKB exome sequencing dataset $(\mathrm{N}=454,796)$ based on the following QC measures ${ }^{20}$ (Figure S4):

(i) DNA contamination: VerifyBAMID freemix (measure of DNA contamination) $>4 \%$.

(ii) Coverage depth: $\geq 10 x$ for $<94.5 \%$ of the consensus coding sequence (CCDS release 22).

(iii) Relatedness: $2^{\text {nd }}$-degree relatives or closer (equivalent to kinship coefficient $>0.0884$ ), as estimated using the --kinship function in KING v2.2.2 23 .

Additionally, to perform analyses accounting for differing genetic ancestry, we assigned samples to one of the four major ancestral groups (minimum 1,000 participants): 
medRxiv preprint doi: https://doi.org/10.1101/2021.12.24.21268381; this version posted December 30, 2021. The copyright holder for this preprint (which was not certified by peer review) is the author/funder, who has granted medRxiv a license to display the preprint in

All rights reserved. No reuse allowed without permission.

354 European $(\mathrm{N}=394,695)$, South Asian $(\mathrm{N}=8,078)$, East Asian $(\mathrm{N}=2,209)$ and African

$355(\mathrm{~N}=7,412)$. This was done by excluding participants: (i) with predicted genetic ancestry

$356<0.99$ (for European ancestry) or $<0.95$ (for the remaining ancestries), as estimated using

357 PEDDY v0.4.2; or (ii) lying outside four standard deviations for the top four principal

358 components for each of the genetic ancestry collections.

359

360 Association analysis for metabolic blood biomarkers

361 A number of stringent variant-level QC steps, detailed previously ${ }^{20}$, were applied to select

362 variant calls with highest confidence for association testing. Briefly, the variant-level QC

363 criteria included coverage depth, genotype and mapping quality scores, DRAGEN variant

364 status, read position rank sum score (RPRS), mapping quality rank sum score (MQRS),

365 alternate allele read proportion for heterozygous calls, proportion of samples failing any of

366 these QC criteria, and gnomAD-related filters.

367 Association testing between the metabolic blood biomarkers and the variants in the

368 exome sequencing dataset was conducted using two complementary analytical approaches

369 (Figure 1):

370 (i) Single variant exome-wide association study (ExWAS)

371 (ii) Gene-level collapsing analysis

372 We conducted the association analyses separately in the European ancestry

373 participants as this comprised the single largest ancestral group in this resource and for all

374 four ancestries combined ('pan-ancestry' analysis).

375

376 Single variant exome-wide association study (ExWAS)

377 In the single-variant analysis (hereafter referred to as 'ExWAS'), variants that passed the QC

378 steps were filtered further to include those that had a minimum of six carriers (equivalent to

379 MAF $>0.0008 \%$ in the European ancestry subset). We additionally excluded variants that had

380 one of the following annotations as their most damaging effect as per SNPEff:

381 3_prime_UTR, 5_prime_UTR, initiator_codon_variant, non_coding_transcript_exon_variant, 
medRxiv preprint doi: https://doi.org/10.1101/2021.12.24.21268381; this version posted December 30, 2021. The copyright holder for this preprint (which was not certified by peer review) is the author/funder, who has granted medRxiv a license to display the preprint in

All rights reserved. No reuse allowed without permission.

382

383

384

385

386

387

388

389

390

391

392

393

394

395

396

397

398

399

400

401

402

403

404

405

406

407

408

409

and synonymous_variant. The remaining non-synonymous coding variants $(\mathrm{N}=2,043,019$ in the European ancestry subset) were used to perform the ExWAS.

The ExWAS was conducted by fitting a linear regression model adjusted for age, sex and BMI (for blood metabolites only), using the tool PEACOK that was developed as a modification of the R package PHESANT ${ }^{34}$. For the pan-ancestry analysis, we additionally included the categorical ancestral group and top five ancestry principal components as covariates. For each of the 198 biomarkers, three different genetic models were evaluated in the ExWAS: (i) genotypic ( $A A$ vs $A B$ vs $B B$ ), (ii) dominant $(A A+A B$ vs $B B$ ), and (iii) recessive ( $A A$ vs $A B+B B$, where $A$ and $B$ denote the reference and alternative alleles, respectively. $A$ significance cut-off of $p<1 \times 10^{-8}$ was adopted for the ExWAS ${ }^{35}$.

\section{$\underline{\text { Gene-level collapsing analysis }}$}

In order to boost power to detect associations for rare variants (including private mutations) having the same direction of effect, we adopted a collapsing framework to test the aggregate effect of rare functional variants in a gene. Overall, 10 different collapsing models ( 9 dominant and one recessive) were implemented per gene to evaluate a range of genetic architectures. Additionally, a synonymous collapsing model was used for the purpose of establishing an empirical negative control ${ }^{20}$.

As outlined in Table S11, the criteria for qualifying variants $(\mathrm{QVs})^{36}$ for the collapsing models were based on the following parameters: type of variant (missense, nonsynonymous or PTV), minor allele frequency, in silico deleteriousness predictors (REVEL and MTR), and type of genetic model (dominant or recessive). The following variant annotations were used to define PTVs: exon_loss_variant, frameshift_variant, start_lost, stop_gained,stop_lost, splice_acceptor_variant, splice_donor_variant, gene_fusion, bidirectional_gene_fusion, rare_amino_acid_variant and transcript_ablation. Hemizygous genotypes for the $\mathrm{X}$ chromosome also qualified for the recessive model.

For a given collapsing model, the effect of $Q V$ s in each gene $(N=18,762)$ was calculated as the difference in the mean of a blood biomarker between carriers and non- 
medRxiv preprint doi: https://doi.org/10.1101/2021.12.24.21268381; this version posted December 30, 2021. The copyright holder for this preprint (which was not certified by peer review) is the author/funder, who has granted medRxiv a license to display the preprint in

All rights reserved. No reuse allowed without permission.

410 carriers of the QVs, using a linear regression model in PEACOCK. Covariates used in the

411 linear regression model were identical to that described for the ExWAS.

412 A significance cut-off of $p<1 \times 10^{-8}$ was set for the collapsing analysis based on the

413 observed $\mathrm{p}$-value distribution for the synonymous model and an n-of- 1 permutation, as

414 described previously ${ }^{20}$.

415

416

\section{Association analysis of clinical phenotypes documented in the UKB}

417 We harmonized and union mapped the clinical phenotypes available in the UKB, as previously

418 described $^{20}$. Phenome-wide collapsing analysis for 15,719 clinical phenotypes was performed

419 for the 11 collapsing models, as described in our previously published study ${ }^{20}$. We queried the

420 results of this analysis for genes of interest that emerged from the analysis of the metabolic

421 biomarkers.

422 Additionally, we also performed an association analysis between the each of the 198 metabolic

423 biomarkers and the clinical phenotypes using a linear regression model adjusted for age and 424 sex.

\section{Comparison of results from collapsing analyses to microarray-based genome-wide} association study

428 We explored the hypothesis that the application of a collapsing framework - that tests the aggregate effect of rare functional variants in a gene identified using exome sequencing detected gene-biomarker relationships that were previously not identified in microarraybased studies. In order to do that, we compared our findings with the results from a recent study ${ }^{14}$ that conducted single variant association analysis (GWAS) for clinical biomarkers in the UKB using microarray data, including directly genotyped coding variants. Besides the 28/30 clinical blood biomarkers that we studied, seven other biomarkers (mainly, urinerelated) were analysed in the GWAS. These seven biomarkers comprised of four urinary biomarkers that were directly measured in the UKB and an additional three derived measurements. For the purpose of comparing findings, we additionally performed gene-level collapsing analysis for the four urinary biomarkers for which data were directly available in 
medRxiv preprint doi: https://doi.org/10.1101/2021.12.24.21268381; this version posted December 30, 2021. The copyright holder for this preprint (which was not certified by peer review) is the author/funder, who has granted medRxiv a license to display the preprint in

All rights reserved. No reuse allowed without permission.

439 the UKB (i.e. 'sodium in urine', 'potassium in urine', 'microalbumin in urine', and 'creatinine

440 (enzymatic) in urine'). To be consistent with the microarray-based GWAS, we used the

441 statin-adjusted values for LDL-cholesterol, total cholesterol, and apolipoprotein B, and the

442 medication-unadjusted values for the remaining biomarkers. Thereafter, for the set of 32

443 biomarkers (28 blood and 4 urinary biomarkers) common to both studies, we compared

444 gene-biomarker relationships that achieved significance $\left(p<1 \times 10^{-8}\right)$ in the collapsing analysis

445 with gene-biomarker relationships corresponding to the significant coding variant

446 associations reported in the GWAS. We considered a comparatively relaxed significance

447 threshold of $p=1 \times 10^{-7}$ for the GWAS results in order to be stringent when attributing a gene-

448 biomarker relationship as being specific to the collapsing analysis.

449 We also hypothesised that the various variant-level "purifying" filters implemented for

450 QV selection in the collapsing analysis can enable a more direct estimate for the effect of

451 gene aberrations (e.g., PTVs) on biomarker levels. To investigate this hypothesis, we

452 compared the effect sizes for gene-biomarker relationships that achieved significance in both

453 the gene-level collapsing analysis and the microarray-based GWAS. For each such gene-

454 biomarker relationship, we selected: (i) the model with the highest absolute beta in the

455 collapsing analysis, and (ii) the individual variant with the highest absolute beta as reported

456 in the Sinnott-Armstrong et al GWAS ${ }^{14}$. For the latter, we adopted the absolute beta

457 estimated in the genotypic model in our ExWAS (for the corresponding gene-biomarker

458 relationship) as a substitute, to account for possible differences in trait transformation,

459 association model or covariates between our study and the Sinnott-Armstrong et al GWAS.

460 Nonetheless, the absolute betas were highly correlated between the Sinnott-Armstrong et al

461 GWAS and our ExWAS (Spearman's rho=0.99) (Figure S5). We then compared the

462 absolute beta of the collapsing model [step (i)] with that of the individual variant [step (ii)].

463 This approach provides a means to compare the effect size of aberrations in genes on

464 biomarker levels estimated from individual coding variants captured by microarrays with that

465 estimated from an aggregate of rare coding variants identified using exome sequencing. 
medRxiv preprint doi: https://doi.org/10.1101/2021.12.24.21268381; this version posted December 30, 2021. The copyright holder for this preprint (which was not certified by peer review) is the author/funder, who has granted medRxiv a license to display the preprint in

All rights reserved. No reuse allowed without permission.

467 Estimating gene similarity based on association signatures from collapsing analysis

468 We aimed to leverage the rich catalogue of gene-level association statistics from the

469 collapsing analysis - ascertained for the set of studied metabolic biomarkers and under

470 different QV models - to identify genes that possess similar metabolic biomarker fingerprint

471 as a (target) gene of interest. Such a 'gene similarity' metric can provide opportunities to not

472 only expand our understanding of gene networks, but also offer alternative candidates in

473 cases of difficult-to-drug targets. Gene-SCOUT (Gene Similarity from Continuous Traits) ${ }^{24}$,

474 the tool that we developed for this purpose, can also estimate "similarity" between genes

475 based on any set of quantitative traits of interest.

476 Rather than calculating similarities between genes directly, Gene-SCOUT estimates

477 distances between genes, which it then uses as a proxy for their similarity. Based on that,

478 the set of genes having the smallest distance from a given seed gene represent those that

479 are most 'similar' to it. We applied the cosine distance method - which is commonly used in

480 natural language processing ${ }^{37}$ - to calculate distances between genes ${ }^{38}$ based on their

481 effects on the metabolic biomarkers (referred to as 'features') estimated in the collapsing

482 analysis. In order to minimise the impact of stochastic effects on the gene similarity

483 estimations, for a given seed gene of interest, only those features that the genes is

484 associated with at $\mathrm{p}<1 \times 10^{-5}$ are selected ('feature selection' step), guided by sensitivity

485 analyses performed for a range of $p$-value thresholds ${ }^{24}$. Thus, distances from genes having

$486 \mathrm{p}>1 \times 10^{-5}$ for all features in common with the seed gene are not considered.

487 The feature set used to generate the Gene-SCOUT results comprised of the 198

488 metabolic blood biomarkers. Though there is a degree of correlation in our feature set

489 (Figure 2a), we have demonstrated through simulations that correlation between features

490 has minimal impact on gene similarity estimations ${ }^{24}$.

491 To illustrate the tool's utility, we generated a network figure showing the genes that were

492 most similar to each of the 24 genes that were significantly associated with LDL-cholesterol

493 in the collapsing analysis. 
medRxiv preprint doi: https://doi.org/10.1101/2021.12.24.21268381; this version posted December 30, 2021. The copyright holder for this preprint (which was not certified by peer review) is the author/funder, who has granted medRxiv a license to display the preprint in

All rights reserved. No reuse allowed without permission.

\section{Ethics Reporting}

495 The protocols for UKB are overseen by The UK Biobank Ethics Advisory Committee (EAC);

496 for more information see: https://www.ukbiobank.ac.uk/ethics/ and

497 https://www.ukbiobank.ac.uk/wp-content/uploads/2011/05/EGF20082.pdf.

498

499

\section{Acknowledgements}

500 We thank the participants and investigators in the UKB study who made this work possible

501 (Resource Application Number 26041); the UKB Exome Sequencing Consortium (UKB-ESC)

502 members AbbVie, Alnylam Pharmaceuticals, AstraZeneca, Biogen, Bristol-Myers Squibb,

503 Pfizer, Regeneron and Takeda for funding the generation of the exome sequence data; the

504 Regeneron Genetics Center for completing the sequencing and initial quality control of the

505 exome sequencing data; and the AstraZeneca Centre for Genomics Research Analytics and

506 Informatics team for processing and analysis of sequencing data.

507

508 Author Contributions

509 S.P. designed the study. A.N., L.M., R.S.D., D.V., E.W., Q.W. and S.P. performed the

510 analyses and statistical interpretation. A.N., R.S.D., A.R.H. and S.P. drafted the manuscript.

511 All authors contributed to the review and critical revision of the manuscript.

512

513 Competing interests

514 A.N., L.M., R.S.D., D.V., E.W., E.L.A., A.R., K.C., K.R.S., Q.W., B.C., D.S.P., A.R.H. and

515 S.P. are current employees and/or stockholders of AstraZeneca. 
medRxiv preprint doi: https://doi.org/10.1101/2021.12.24.21268381; this version posted December 30, 2021. The copyright holder for this preprint (which was not certified by peer review) is the author/funder, who has granted medRxiv a license to display the preprint in perpetuity.

All rights reserved. No reuse allowed without permission.

\section{References}

516 1. Willer, C. J. et al. Discovery and refinement of loci associated with lipid levels. Nature

517 genetics 45, (2013).

518 2. Wuttke, M. et al. A catalog of genetic loci associated with kidney function from

$519 \quad$ analyses of a million individuals. Nature genetics 51, (2019).

520 3. Kettunen, J. et al. Genome-wide association study identifies multiple loci influencing

521

522

523

524

525

526

527

528

529

530

531

532

533

534

535

536

537

538

539

540

541

542

543

544

545

546

547

548

549

550

551

552

553

554

555

556

557

558

559

560

561

562

563

564

565

566

4. Yet, I. et al. Genetic Influences on Metabolite Levels: A Comparison across Metabolomic Platforms. PloS one 11, (2016).

5. Suhre, K. et al. A genome-wide association study of metabolic traits in human urine. Nature genetics 43, (2011).

6. Shin, S.-Y. et al. An atlas of genetic influences on human blood metabolites. Nature genetics 46, (2014).

7. Klarin, D. et al. Genetics of blood lipids among $\sim 300,000$ multi-ethnic participants of the Million Veteran Program. Nature genetics 50, (2018).

8. Chambers, J. C. et al. Genome-wide association study identifies loci influencing concentrations of liver enzymes in plasma. Nature genetics 43, (2011).

9. Prins, B. P. et al. Genome-wide analysis of health-related biomarkers in the UK Household Longitudinal Study reveals novel associations. Scientific reports 7, (2017).

10. Wheeler, E. et al. Impact of common genetic determinants of Hemoglobin A1c on type 2 diabetes risk and diagnosis in ancestrally diverse populations: A transethnic genome-wide meta-analysis. PLoS medicine 14, (2017).

11. Long, T. et al. Whole-genome sequencing identifies common-to-rare variants associated with human blood metabolites. Nature genetics 49, (2017).

12. Gallagher, M. D. \& Chen-Plotkin, A. S. The Post-GWAS Era: From Association to Function. American journal of human genetics 102, (2018).

13. Bycroft, C. et al. The UK Biobank resource with deep phenotyping and genomic data. Nature 562, 203-209 (2018).

14. Sinnott-Armstrong, N. et al. Genetics of 35 blood and urine biomarkers in the UK Biobank. Nature genetics 53, (2021).

15. UK10K Consortium et al. The UK10K project identifies rare variants in health and disease. Nature 526, (2015).

16. MacArthur, D. G. et al. A systematic survey of loss-of-function variants in human protein-coding genes. Science (New York, N.Y.) 335, (2012).

17. Ritchie, S. C. et al. Quality control and removal of technical variation of NMR metabolic biomarker data in $\sim 120,000$ UK Biobank participants. medRxiv 2021.09.24.21264079 (2021) doi:10.1101/2021.09.24.21264079.

18. Gandotra, S. et al. Perilipin deficiency and autosomal dominant partial lipodystrophy. The New England journal of medicine 364, (2011).

19. Shin, G.-C., Kang, H. S., Lee, A. R. \& Kim, K.-H. Hepatitis B virus-triggered autophagy targets TNFRSF10B/death receptor 5 for degradation to limit TNFSF10/TRAIL response. Autophagy 12, (2016).

20. Wang, Q. et al. Rare variant contribution to human disease in 281,104 UK Biobank exomes. Nature (2021) doi:10.1038/s41586-021-03855-y.

21. Aimee M. Deaton et al. Gene-level analysis of rare variants in 379,066 whole exome sequences identifies an association of GIGYF1 loss of function with type 2 diabetes. Scientific Reports 11, (2021).

22. Jurgens, S. J. et al. Rare Genetic Variation Underlying Human Diseases and Traits: Results from 200,000 Individuals in the UK Biobank. bioRxiv 2020.11.29.402495 (2020) doi:10.1101/2020.11.29.402495.

23. Chen, J. et al. The trans-ancestral genomic architecture of glycemic traits. Nature genetics 53, (2021). 
medRxiv preprint doi: https://doi.org/10.1101/2021.12.24.21268381; this version posted December 30, 2021. The copyright holder for this preprint (which was not certified by peer review) is the author/funder, who has granted medRxiv a license to display the preprint in

All rights reserved. No reuse allowed without permission.

24. Lawrence Middleton et al. Gene-SCOUT: identifying genes with similar continuous trait fingerprints from phenome-wide association analyses. Nucleic Acids Res (in submission) (2021).

25. Cohen, J. C., Boerwinkle, E., Mosley, T. H. \& Hobbs, H. H. Sequence variations in PCSK9, low LDL, and protection against coronary heart disease. The New England journal of medicine 354, (2006).

26. Abul-Husn, N. S. et al. A Protein-Truncating HSD17B13 Variant and Protection from Chronic Liver Disease. The New England journal of medicine 378, (2018).

27. Akbari, P. et al. Sequencing of 640,000 exomes identifies GPR75 variants associated with protection from obesity. Science (New York, N.Y.) 373, (2021).

28. Nag, A. et al. Human genetic evidence supports MAP3K15 inhibition as a therapeutic strategy for diabetes. medRxiv 2021.11.14.21266328 (2021) doi:10.1101/2021.11.14.21266328.

29. Szustakowski, J. D. et al. Advancing human genetics research and drug discovery through exome sequencing of the UK Biobank. Nature genetics 53, (2021).

30. Cingolani, P. et al. A program for annotating and predicting the effects of single nucleotide polymorphisms, SnpEff: SNPs in the genome of Drosophila melanogaster strain w1118; iso-2; iso-3. Fly 6, 80-92 (2012).

31. Traynelis, J. et al. Optimizing genomic medicine in epilepsy through a genecustomized approach to missense variant interpretation. Genome research 27, 17151729 (2017).

32. loannidis, N. M. et al. REVEL: An Ensemble Method for Predicting the Pathogenicity of Rare Missense Variants. American journal of human genetics 99, 877-885 (2016).

33. Manichaikul, A. et al. Robust relationship inference in genome-wide association studies. Bioinformatics 26, (2010).

34. Millard, L. A. C., Davies, N. M., Gaunt, T. R., Davey Smith, G. \& Tilling, K. Software Application Profile: PHESANT: a tool for performing automated phenome scans in UK Biobank. International journal of epidemiology 47, (2018).

35. Fadista, J., Manning, A. K., Florez, J. C. \& Groop, L. The (in)famous GWAS P-value threshold revisited and updated for low-frequency variants. European journal of human genetics: EJHG 24, (2016).

36. Petrovski, S. et al. An Exome Sequencing Study to Assess the Role of Rare Genetic Variation in Pulmonary Fibrosis. American journal of respiratory and critical care medicine 196, (2017).

37. Huang A. Similarity Measures for Text Document Clustering. NZCSRSC (2008).

38. Kittipong Chomboon, Pasapitch Chujai, Pongsakorn Teerarassamee, Kittisak Kerdprasop \& Nittaya Kerdprasop. An Empirical Study of Distance Metrics for kNearest Neighbor Algorithm. Proceedings of the 3rd International Conference on Industrial Application Engineering (2015). 